\title{
Gestational Diabetes Mellitus: Impact of Maternal Blood Sugar Level and BMI on Foetal Birth Weight
}

\author{
Dr. Bipul Prasad Deka ${ }^{1}$, Dr. Dimpy Begum ${ }^{2}$ \\ ${ }^{1}$ Assistant Professor, Assam Medical College \&Hospital, Dibrugarh, Assam \\ ${ }^{2}$ Former Post graduate trainee, Gauhati Medical College, Guwahati, Assam \\ *Corresponding author - Dr. Bipul Prasad Deka, bipuldeka012@ gmail.com
}

Received 31 January 2019; $\quad$ Accepted 22 February 2019;

Published 24 February 2019

\begin{abstract}
Gestational diabetes mellitus (GDM) is defined as glucose intolerance of variable degrees with an onset, or first recognized, during pregnancy. About $15-45 \%$ of babies born to diabetic mothers can have macrosomia. This prospective case control study was conducted in the department of Obstetrics and Gynaecology of Gauhati medical college and hospital, Guwahati, Assam during the period of 2013-2015. A total of 160 patients were included in the study. 100 patients without any glucose abnormality were taken as control and 60 patients with gestational diabetes mellitus were included in the study as cases. In this study it was found that mean birth weight in GDM cases is more than normoglycemic control. The overweight and obesity group (BMI>25) have maximum birth weight. In this study it was found that the fasting blood glucose level is maximum in mothers with baby birth weight $>3.5 \mathrm{~kg}$.
\end{abstract}

Keywords: Gestational diabetes mellitus, overweight, obesity, mean birth weight, body mass index.

\section{Introduction}

Gestational diabetes mellitus (GDM) is defined as glucose intolerance of variable degrees with an onset, or first recognized, during pregnancy. About $15-45 \%$ of babies born to diabetic mothers can have macrosomia, which is a 3 -fold higher rate when compared to normoglycemic controls. Macrosomia is typically defined as a birth weight above the 90th percentile for gestational age or $>4,000 \mathrm{~g} .{ }^{[1]}$ Maternal obesity is associated with gestational diabetes mellitus (GDM) and adverse pregnancy outcomes. ${ }^{[2-5]}$ When obese women were compared to normal-weight women, the newborns of obese women had more than double the risk of macrosomia compared to those of women with normal weight. ${ }^{[6]}$ Most studies addressing the effects of maternal BMI on pregnancy outcomes include women with GDM. ${ }^{[7,8]}$ In gravidas who are diabetic and in those who are not, there is a significant relation among increased maternal glucose levels, greater fetal growth, and higher infant weight at birth. ${ }^{[9-14]}$ Maternal hyperglycemia leads to excess fetal insulin, itself a growth hormone for the fetus. Thus, offspring of mothers with gestational diabetes mellitus (GDM) have higher birth weights. ${ }^{[15]} \mathrm{A}$ study has shown that maternal obesity is a stronge predictor of a large-for-gestational-age infant than maternal hyperglycemia. ${ }^{[16]}$ In the HAPO study the investigators found that the frequency of macrosomia in GDM was increased by $50 \%$ compared to non-GDM in both the nonobese and obese groups. Obesity was associated with a 2-fold higher frequency of macrosomia whether in the non-GDM or GDM group. Macrosomia in GDM only was present in $26 \%$, in GDM plus obesity in $33 \%$ and in obesity only in $41 \%$ women. Women who did not have GDM but who were obese had a $13.6 \%$ increased risk of macrosomia (defined as a child weighing $4,000 \mathrm{~g}$ or more at birth) than nonobese women. ${ }^{[17]}$

\section{Aims and objectives}

The objective of this study were to examine association of birth weight with maternal blood glucose level and body mass index(BMI) in gestational diabetes mellitus cases and to determine the extent to which the effect of GDM is explained by its influence on birth weight or by maternal adiposity.

\section{Methods and materials}

This was a prospective case control study conducted in the department of Obstetrics and Gynaecology of Gauhati medical college and hospital, Guwahati, Assam during the period of 20132015. A total of 160 patients were included in the study. 100 patients without any glucose abnormality were taken as control and 60 patients with gestational diabetes mellitus were included in the study as cases.

Eligibility criteria included patients attending antenatal OPD or admitted in the ward at term pregnancy.

Exclusion criteria - cases with insufficient information - where last menstrual period was not known, cases with severe anaemia, cases with twin pregnancy, cases with chronic hypertension, 
chronic renal disease, cases having proteinuria before 20 weeks of gestation, cases diagnosed diabetes before pregnancy, cases where $5 \%$ dextrose drips were used and cases of prolonged labour were excluded. BMI was measured at the 1 st visit in antenatal period.

\section{Results and observations}

Table 1: Distribution of patients

\begin{tabular}{|c|c|c|c|}
\hline Serial no & Group & No. Of cases $\mathrm{n}=160$ & Percentage \\
\hline 1 & Control & 100 & 62.50 \\
\hline 2 & Cases & 60 & 37.50 \\
\hline
\end{tabular}

Table 2: Age distribution

\begin{tabular}{|l|c|c|}
\hline Age group & Control & Cases \\
\hline 15-20 years & 10 & 0 \\
\hline 21-25 years & 18 & 06 \\
\hline 26-30 years & 42 & 22 \\
\hline$>30$ years & 30 & 32 \\
\hline
\end{tabular}

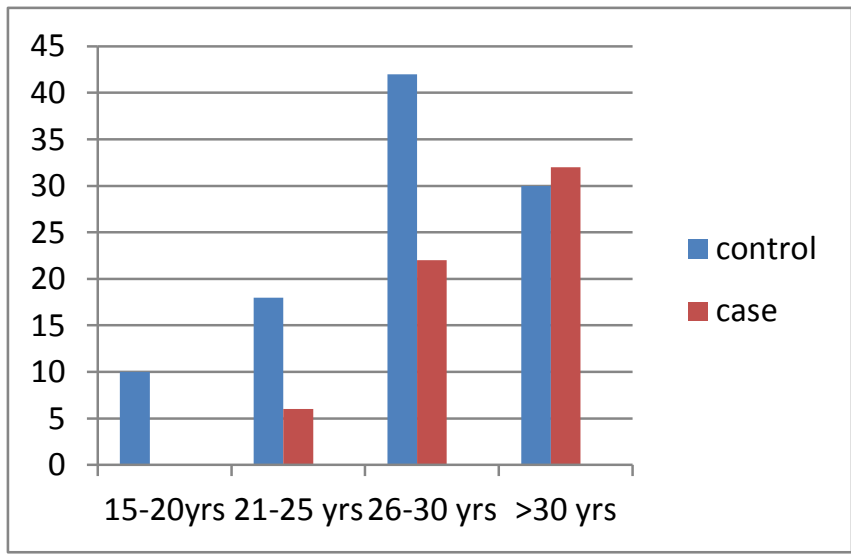

Table 3: Distribution of parity among control and cases

\begin{tabular}{|l|c|c|}
\hline Parity & Control & Cases \\
\hline Primi & 40 & 42 \\
\hline Para 1-3 & 48 & 18 \\
\hline Para 4 and above & 12 & 0 \\
\hline Total & 100 & 60 \\
\hline
\end{tabular}

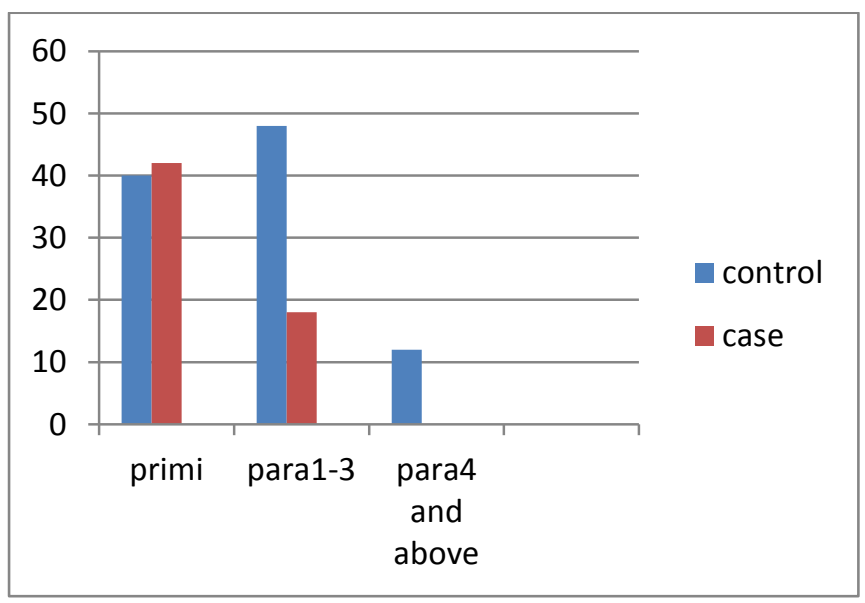

Table4: distribution of cases depending on BMI

\begin{tabular}{|l|c|c|c|}
\hline category & $\begin{array}{c}\text { BMI } \\
\left(\mathrm{kg} / \mathrm{m}^{2}\right)\end{array}$ & \multicolumn{2}{|c|}{$\begin{array}{c}\text { No of cases } \\
(\mathrm{N}=60)\end{array}$} \\
\hline Underweight & $<18.5$ & \multicolumn{2}{|c|}{05} \\
\hline Normal & $18.5-24.9$ & 21 \\
\hline Overweight and obese & $>25$ & 34 \\
\hline
\end{tabular}

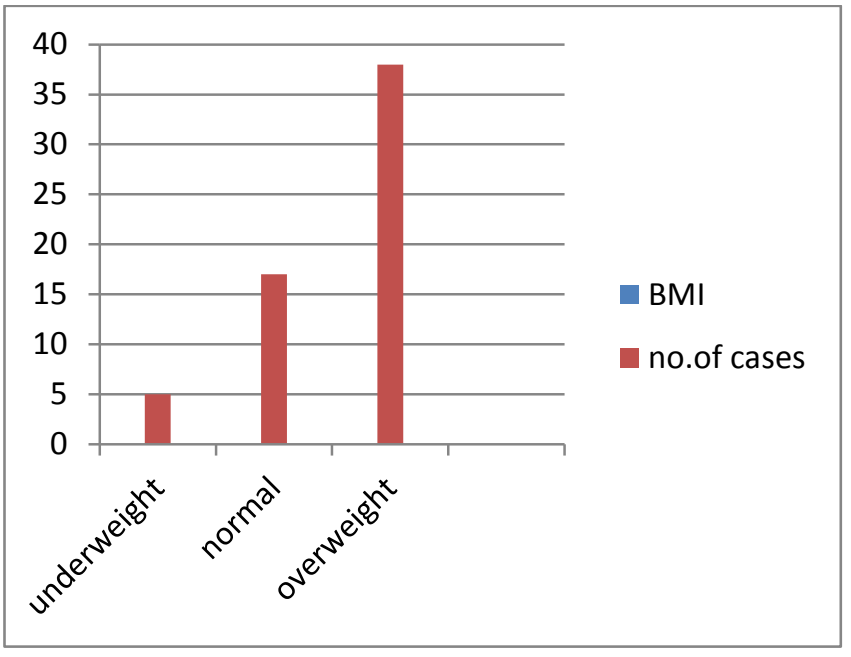

Table 5: Relation of maternal fasting blood glucose level with foetal birth weight in control group

\begin{tabular}{|l|c|c|}
\hline $\begin{array}{c}\text { Birth weight in } \\
\mathrm{kg}\end{array}$ & $\begin{array}{c}\text { No. Of } \\
\text { patients }\end{array}$ & $\begin{array}{c}\text { Mean maternal fasting blood } \\
\text { glucose }(\mathrm{mg} \%)\end{array}$ \\
\hline Upto $2.5 \mathrm{~kg}$ & 8 & 71.3 \\
\hline $2.6-3 \mathrm{~kg}$ & 38 & 72.9 \\
\hline $3.1-3.5 \mathrm{~kg}$ & 44 & 78.9 \\
\hline$>3.5 \mathrm{~kg}$ & 10 & 87 \\
\hline
\end{tabular}

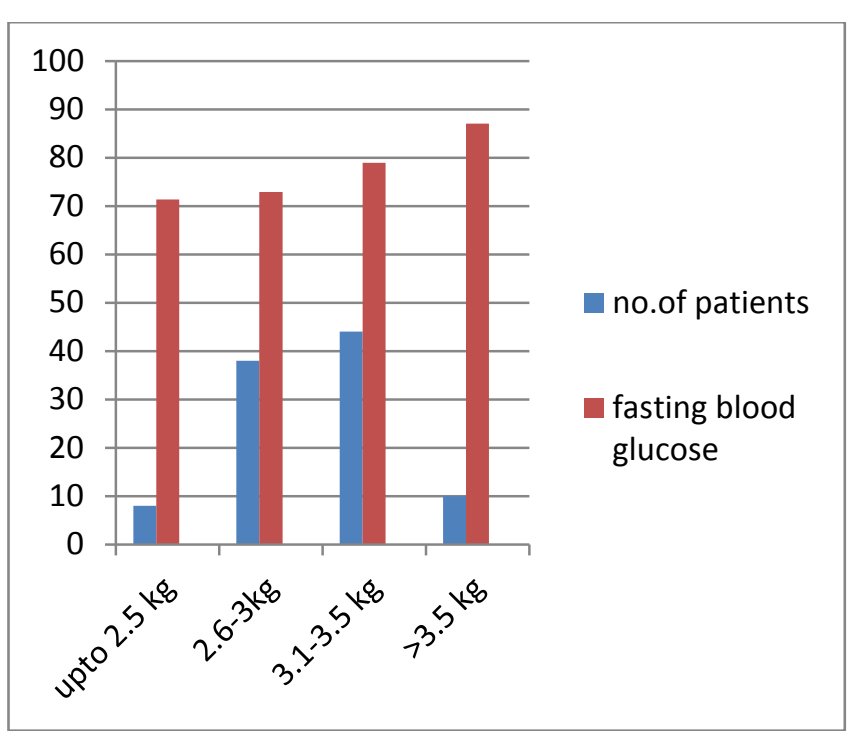

Table 6: Relation of maternal fasting blood glucose level and foetal birth weight in gestational diabetic cases

\begin{tabular}{|c|c|c|}
\hline $\begin{array}{c}\text { Foetal birth } \\
\text { weight }\end{array}$ & $\begin{array}{l}\text { No. of } \\
\text { cases }\end{array}$ & $\begin{array}{l}\text { Maternal fasting blood } \\
\text { glucose level (mg\%) }\end{array}$ \\
\hline Upto $2.5 \mathrm{~kg}$ & 05 & 101 \\
\hline $2.6-3 \mathrm{~kg}$ & 12 & 104 \\
\hline $3.1-3.5 \mathrm{~kg}$ & 20 & 115 \\
\hline \multicolumn{2}{|c|}{$>3.5 \mathrm{~kg}$} & 122 \\
\hline
\end{tabular}

In the table it is seen that babies birth weight $>3.5 \mathrm{~kg}$ have maximum fasting blood glucose levels.

Table7: Relation of foetal birth weight to BMI

\begin{tabular}{|c|c|c|}
\hline BMI $\left(\mathrm{kg} / \mathrm{m}^{2}\right)$ & $\begin{array}{c}\text { No. of cases } \\
(\mathrm{N}=60)\end{array}$ & $\begin{array}{c}\text { Mean foetal birth } \\
\text { weight }(\mathrm{kg})\end{array}$ \\
\hline Underweight $(<18.5)$ & 05 & 2.55 \\
\hline Normal $(18.5-24.9)$ & 21 & 3.35 \\
\hline Overweight and obese $(>25)$ & 34 & 3.75 \\
\hline
\end{tabular}




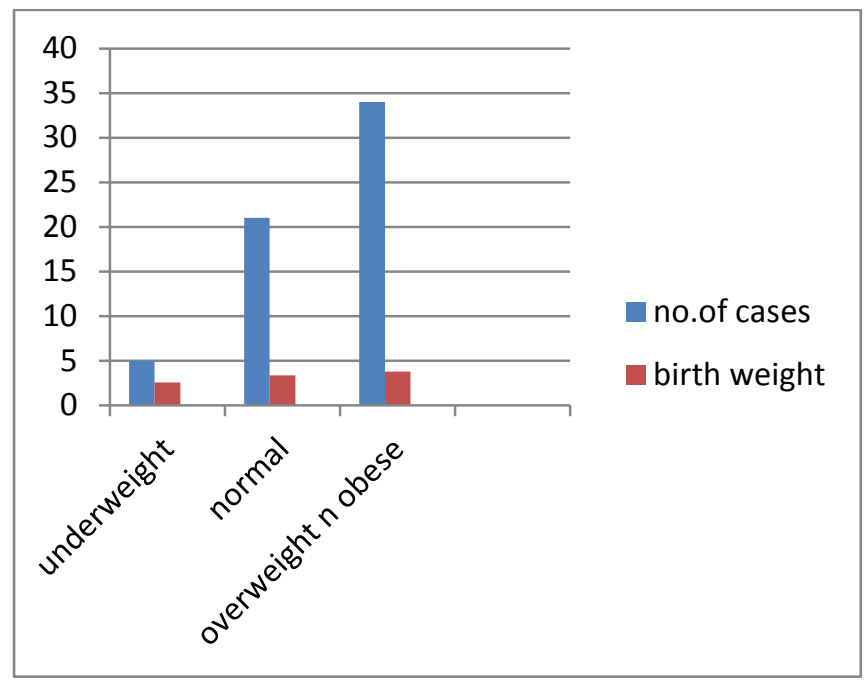

Overweight and obese women have babies with maximum birth weight.

Table 8: Relation of mean maternal fasting blood glucose level and mean birth weight in normal and gestational diabetic women

\begin{tabular}{|l|c|c|c|}
\hline Group & Number & $\begin{array}{c}\text { Maternal fasting } \\
\text { glucose }(\mathrm{mg} \%)\end{array}$ & $\begin{array}{c}\text { Mean birth } \\
\text { weight }(\mathrm{kg})\end{array}$ \\
\hline Control & 100 & 83.52 & 3.11 \\
\hline Cases & 60 & 112.4 & 3.51 \\
\hline$P<0.05$
\end{tabular}

$P<0.05$

There is significant difference in maternal fasting blood glucose and birth weight between control group and GDM group.

\section{Discussion}

\section{Relation of birth weight in control and GDM cases:}

Following studies shows that mean birth weight in GDM cases is more than normoglycemic control .The difference is statistically significant.

A)
\begin{tabular}{|l|l|l|}
\hline Group & $\begin{array}{l}\text { Goldberg J.D.et } \\
\text { al }(1986)^{18} \\
\text { N=58 }\end{array}$ & Present study \\
\cline { 2 - 3 } & $\begin{array}{l}\text { Baby birth } \\
\text { weight mean(gm) }\end{array}$ & $\begin{array}{l}\text { Baby birth } \\
\text { weight } \\
\text { mean(gm) }\end{array}$ \\
\hline 1.control(normoglycemic) & $3231 \_+561$ & 3110 \\
\hline 2.gestational diabetes & $3597 \_+721$ & 3511 \\
\cline { 2 - 3 } & $\mathrm{P}<0.05$ & $\mathrm{P}<0.05$ \\
\hline
\end{tabular}

B)

\begin{tabular}{|l|c|c|}
\hline Group & $\begin{array}{c}\text { Mutangala Muloye } \\
\text { Guy }^{\mathbf{2 0}} \mathbf{( 2 0 1 7 )}\end{array}$ & Present study \\
\cline { 2 - 3 } & $\begin{array}{c}\text { Baby birth weight } \\
\text { mean(gm) }\end{array}$ & $\begin{array}{c}\text { Baby birth weight } \\
\text { mean(gm) }\end{array}$ \\
\hline $\begin{array}{l}\text { 1.Non } \\
\text { GDM(control) }\end{array}$ & $4156 \_+165$ & 3110 \\
\hline $\begin{array}{l}\text { 2.Gestational } \\
\text { diabetes }\end{array}$ & $4182 \_+177$ & 3511 \\
\cline { 2 - 3 } & $\mathrm{P}=.001$ & $\mathrm{P}<0.05$ \\
\hline
\end{tabular}

Jeanette wahlberg et $\mathrm{al}^{[20]}$ in their study also found that GDM women had higher mean infant birth weight compared with controls(3682gm VS 3541gm .P<0.001).

\section{Relation of BMI and foetal birth weight:}

In our study it was found that the overweight and obesity group (BMI>25) have maximum birth weight.

Michael Conall Dennedy et al ${ }^{[19]}$ (2012) concluded that birthweight correlated with maternal BMI was higher in infants born to overweight mothers( mean difference $0.9 \mathrm{~kg}$ ) and obese mothers when compared with offspring of women with normal BMI ( $\mathrm{P}<0.001$ ). $22 \%$ infants born to obese mothers and $16 \%$ born to overweight mothers were large for gestational age compared with $12 \%$ born to mothers with normal BMI.

Liu Jian et $\mathrm{al}^{[24]}$ in their study concluded that High BMI measured at GDM screening was the most important determinant for risk of macrosomia.

Martin kate E,M Rosalie et $\mathrm{al}^{[25]}$ in their study on maternal BMI and GDM on pregnancy outcome, found that Raised maternal BMI is a risk factor for high infant birth weight and incidence of birth weight $>90 \%$ (RR $1.38 ; 95 \%$ CI 1.07 to $1.77 ; \mathrm{p}=0.01$ ) was significantly increased in women who were obese, independent of GDM.

\section{3) Relation of maternal blood glucose with birth weight}

In our study it was found that the fasting blood glucose level is maximum in mothers with baby birth weight $>3.5 \mathrm{~kg}$.

OdedLangerMDRogerMazzePhD ${ }^{[22]}$ in their study found that the severity of glucose intolerance (hyperglycemia) was found to be associated with both maternal and neonatal morbidity in terms of infant size and cesarean section rate. By use of hierarchical cluster analysis to identify three groups on the basis of control levels (low $<87 \mathrm{mg} / \mathrm{dl}$, mid 87 to $105 \mathrm{mg} / \mathrm{dl}$, high >105 mg/dl) we were able to show a positive outcome in the low group with reduced rates of large-for-gestational-age (2\%) and macrosomic (0\%) infants. Furthermore, they showed that as mean blood glucose levels and instability in glycemic control increased from group to group, incidence of large-for-gestational-age and macrosomic infants increased.

Jeanette et $\mathrm{al}^{[21]}$ in their study found that birth weight positively correlated with fasting blood glucose level at GDM diagnosis $(\mathrm{P}<0.001)$.

Seabra Gisele et $\mathrm{al}^{[23]}$ in their study found that higher fasting glucose levels were found in the second semester for women whose infants had macrosomia than for women whose newborns were normal weight $(86.2 \mathrm{mg} / \mathrm{dL}$ and $78.8 \mathrm{mg} / \mathrm{dL}$; post hoc $=$ $0.003)$.

\section{Conclusion}

In GDM the birth weight is significantly more than normal mothers. Increased BMI is a risk factor for large for gestational age infant. As the BMI increases there is increase in birth weight. Increased fasting blood glucose level is another risk factor for increased birth weight.

\section{References}

[1] K C Kamana et al: gestational diabetes mellitus and macrosomia: A literature review. Ann nutr metab 2015; 66 (suppl 2):14-20. 
[2] 2007 Saving mothers' lives: reviewing maternal deaths to make motherhood safer, 2003-2005. In: Lewis G, ed. London: Centre for Maternal and Child Enquiries (CEMACH)

[3] 2010 Dietary interventions and physical activity interventions for weight management before, during and after pregnancy. Public health guidance PH27. London: National Institute for Health and Clinical Excellence.

[4] Modder J, Fitzsimons KJ 2010 CMACE/RCOG Joint Guideline: Management of Women with Obesity in Pregnancy. London: Centre for Maternal and Child Enquiries (CMACE); Royal College of Obstetricians and Gynaecologists (RCOG)

[5] Fitzsimons KJ, Modder J 2010 Setting maternity care standards for women with obesity in pregnancy. Semin Fetal Neonatal Med 15:100-107

[6] Knopp RH. Hormone-mediated changes in nutrient metabolism in pregnancy: a physiological basis for normal fetal development. Ann N Y Acad Sci 1997;817:251-71.

[7] Heslehurst N, Simpson H, Ells LJ, Rankin J, Wilkinson J, Lang R,Brown TJ, SummerbellCD2008 The impact of maternal BMIstatus.

[8] Catalano PM, Ehrenberg HM 2006 The short- and longterm implications of maternal obesity on the mother and her offspring.

BJOG 113:1126-1133on pregnancy outcomes with immediate short-term obstetric resource implications: a meta-analysis. Obes Rev 9:635-683

[9] Pedersen J. Weight and length at birth of infants of diabetic mothers. Acta Endocrinol 1954;16:330-42.

[10] Sermer M, Naylor D, Gare DJ, et al. Impact of increasing carbohydrate intolerance on maternal-fetal outcomes in 3637 women without gestational diabetes. Am J Obstet Gynecol1995;173:146-56.

[11] Farmer G, Russell G, Hamilton-Nicol DR, et al. The influence of maternal glucose metabolism on fetal growth, development and morbidity in 917 singleton pregnancies in non diabetic women. Diabetologia 1988;31:134-41.

[12] Jovanovic-Peterson L, Peterson CM, Reed GF, et al. Maternal postprandial glucose levels and infant birth weight: the Diabetes in Early Pregnancy Study. The National Institute of Child Health and Human Development-Diabetes in Early Pregnancy Study. Am J Obstet Gynecol 1991; 164:103-11.

[13] Tallarigo L, Giampietro O, Penno G, et al. Relation of glucose tolerance to complications of pregnancy in non diabetic women. N Engl J Med 1986; 315:989-92. 38

[14] Scholl TO, Sowers M, Chen X, et al. Maternal glucose concentration influences fetal growth, gestation, and pregnancy complications. Am J Epidemiol 2001;154:514-20.
[15] Silverman BL, Rizzo T, Cho NH, et al. Long-term prospective evaluation of offspring of diabetic mothers. Diabetes. 1991; 40:121-125.

[16] Ryan EA: Diagnosing gestational diabetes. Diabetologia 2011; 54: 480-486

[17] Metzger BE, Lowe LP, Dyer AR, et al: The Hyperglycemia and Adverse Pregnancy Outcome (HAPO) study: associations of higher levels of maternal glucose and BMI with macrosomia: an example of diabesity. ADA 70th Scientific Session, 2010. Abstract No. 154-OR. http://professional.diabetes. org/Abstracts _Display. aspx? TYP=1\&CID= 7 Goldberg JD, Franklin B

[18] Goldberg JD, Franklin B, Lasser D, Jornsay DL, Hausknecht RU, Ginsberg-Fellner F, Berkowitz RL Gestational diabetes: impact of home glucose monitoring on neonatal birth weight. Am J Obstet Gynecol. 1986 Mar;154(3):546-50

[19] Muloye Guy Mutangala, Idi Yves Isango et al: Effect of Gestational Diabetes Mellitus on Macrosomia Infants ; Int J Cur Res Rev | Vol 9 • Issue 4 • February 2017:4

[20] Wahlberg Jeanette, ekman bertil, nystrom lennarth, hanson ulf, person bengt, arnqvist hans j:gestational diabetes: glycaemic predictors for fetal macrosomia and maternal risk of future diabetes; clinical practice:april2006;114vol:99-105

[21] Dennedy Michael Conall , Avalos Gloria, W. MiO'Sullivan,,chael, O'Reilly, P Eoin, Gaffne Geraldiney, Dunne Fidelma: ATLANTIC-DIP: Raised Maternal Body Mass Index (BMI)Adversely Affects Maternal and Fetal Outcomes in Glucose-Tolerant Women According to International Association of Diabetes and Pregnancy Study Groups(IADPSG) Criteria J Clin Endocrinol Metab, April 2012, 97(4):E608-E612

[22] Liu J, Leng J, Tang C, et al. Maternal glucose level and body mass index measured at gestational diabetes mellitus screening and the risk of macrosomia: results from a perinatal cohort study. BMJ Open 2014; 4:e004538. doi:10.1136/bmjopen-2013-004538.

[23] Martin kate E,M Rosalie et al .The influence of maternal BMI and gestational diabetes on pregnancy outcome; Diabetes research and clinical practice: june 2015;108 vol:508-513

[24] langer oded, mazze Roger. The relationship between large-for-gestational-age infants and glycemic control in women with gestational diabetes American journal of Obstetrics and Gynecology Volume 159, Dec 1988;6 issue: $1478-1483$

[25] Seabra Gisele, Saunders Cláudia et al. Association between maternal glucose levelsduring pregnancy and gestational diabetes mellitus: an analytical crosssectional study; Diabetology \& Metabolic Syndrome (2015) 7:17 